\title{
Water budget comparison of global climate models and experimental data in Onça Creek basin, Brazil
}

\author{
D. C. D. MELO, I. S. P. MARIN \& E. WENDLAND \\ Department of Hydraulics and Sanitary Engineering, University of São Paulo, 400 Trabalhador são carlense av., \\ São Carlos, Brazil \\ melo.dcd@gmail.com
}

\begin{abstract}
Groundwater is an important part of the hydrological cycle, accounting for more than $25 \%$ of human needs on the global scale. As a result of aquifer overexploitation associated with climate change, even in the most conservative future climate scenarios, mean water-table levels can experience drastic drops. Although there are efforts to include groundwater dynamics in global climate models (GCMs), its influence is still not taken into full account in GCM water budgets, although it is as important as the other water sources considered. To assess the role of percolation in the water balance, we compared the water budget from climate forcing scenarios using $10 \mathrm{GCMs}$ with the water budget from experimental data of a basin in São Paulo state, Brazil. We used the delta factor approach to correct the bias of the model's temperature and precipitation for a control period from 1970 to 1999 , and calculated evapotranspiration using the Thornthwaite method. Experimental data for runoff and interception were derived for the basin's representative crops (sugar cane and pasture) for both water budgets. As the GCMs ignore subsurface flow and the only input considered is precipitation and snow melt, the excess surface water is assumed to be redistributed among the other water budget components. The experimental data shows that there is enough available water for infiltration, indicating that recharge cannot be ignored in the water balance. This leads to the possibility of the models' overestimating the other components to compensate for the ignored recharge.
\end{abstract}

Key words groundwater; global climate models; water budget

\section{INTRODUCTION}

Groundwater plays an important role in supplying fresh water for human needs. Clark et al. (1996) estimated that more than 1.5 billion people already relied on this water source in the $1990 \mathrm{~s}$. Its exploration has increased in the past 50 years, and is expected to increase to sustain the increasing population and economic activities (Konikow 2011). The predicted climate changes may exacerbate this scenario, having a serious impact on groundwater resources. Anomalies in precipitation and temperature patterns, caused by climate change, can alter recharge rates, leading to an even more accelerated depletion of aquifer resources.

Understanding these impacts on groundwater is paramount to preserve and mitigate the possible impacts for future generations (Kløve et al. 2013). Groundwater abstraction is also a relevant process for sea level rise, especially since 1950 (Konikow 2011). From 1900 to 2008 the groundwater depletion was around $4500 \mathrm{~km}^{3}$, equivalent to a sea level rise (SLR) of $12.6 \mathrm{~mm}$ (or around $6 \%$ of the total sea level rise). The average groundwater extraction rate was $145 \mathrm{~km}^{3}$ per year in the period 2000-2008, equivalent to $13 \%$ of the sea level rise (Konikow 2011).

The current global climate models (GCM) generally take into account groundwater as a separate process (Barthel et al. 2012). Usually studies that aim to understand the behaviour of groundwater with changes in climate take as input the temperature and precipitation series from GCMs and calculate the other water balance variables, such as evapotranspiration and runoff, with different methods. Although GCMs can be powerful tools for assessing climate change and climate change impacts, simulated climatic variables inherit some bias that can be corrected through simple methods.

The approach of taking GCM outputs for hydrological studies, even when successful, is insufficient to correctly describe several important features of groundwater systems (Jackson et al. 2011). Using the data from the GCMs, a water balance can be calculated to infer the importance of groundwater in all the hydrologic processes. This water balance can then be compared with experimental data to verify the simulated processes and indicate ways to improve the simulations. In this work, rainfall and temperature time series from $10 \mathrm{GCMs}$ were used to calculate the water balance. The obtained results were compared to actual measured variables in a control basin. 


\section{METHODS}

\section{Climatic data and bias correction}

Monthly precipitation and temperature series from 10 GCMs (BCM, CCSM3, CGCM T47, CNRM CM3, GFDL CM 2.0, GFDL CM2.1, INGV SXG, INM CM3.0, MRI CGCM 2.3.2, MIROC $\mathrm{H}$ ) were bias corrected using the modification factor principle (MF). The GCMs were selected from those provided by Phase 3 of the Coupled Model Intercomparison Project, used in the Fourth Assessment Report of the Intergovernmental Panel on Climate Change (IPCC 2007). The MF method chosen was modified in terms of the perturbation of the $\mathrm{P}$ and $\mathrm{T}$ series. There is a certain limitation when the series are perturbed, as the series keep a strong correlation with the observed data. We propose to enhance the perturbation of the synthetic series starting from the existing anomalies between the observed and simulated series for the control period 1970 to 1989 . Using this approach, bias correct precipitation $\left(P_{b c, m}\right)$ and temperature $\left(T_{b c, m}\right)$ in month $m$ for 1990 to 1999 were calculated by equations (1) and (2).

$$
\begin{aligned}
& P_{b c, m}=P_{g c m, m} \times\left(\frac{\bar{P}_{o b s, m}^{c o n t}}{\bar{P}_{g c m, m}^{c o n t}}\right) \\
& T_{b c, m}=T_{g c m, m}+\left(\bar{T}_{o b s, m}^{c o n t}-\bar{T}_{g c m, m}^{c o n t}\right)
\end{aligned}
$$

Here, $\bar{P}_{o b s, m}^{c o n t}$ and $\bar{T}_{o b s, m}^{c o n t}$ are the mean of observed precipitation and temperature for month $m$; $\bar{P}_{g c m, m}^{c o n t}$ and $\bar{T}_{g c m, m}^{c o n t}$ are the mean of simulated precipitation and temperature given by a model $\mathrm{gcm}$ for month $m ; P_{g c m, m}$ and $T_{g c m, m}$ are the GCM's original monthly precipitation and temperature, respectively.

\section{Experimental site}

The experimental site is located in southeastern Brazil, in São Paulo state. It is composed of two areas, $5 \mathrm{~km}$ from each other, equipped with weather stations. The first site has a station that has collected climatological data since the 1970s. The second has an automatic weather station, installed in 2012, and two runoff plots under different plantings: pasture and sugar cane. The monthly precipitation used as input to the water budget for the sugar cane planting was lower than the total amount due to leaf interception, which reached up to $40 \%$ of total precipitation (Youlton and Wendland 2012). No interception was considered for pasture. Thus, rainfall and temperature (used to calculate evapotranspiration) time series from the climatological station of the first site were used to calculate the water budget.

\section{Water budget}

The Thornthwaite-Mather procedure was applied to run the water budget for two different crops: sugar cane and pasture. This method can be used for several different purposes, such as estimating recharge (Steenhuis and Vandermolen 1986) and to assess climatic scenarios impacts on hydrological systems (Jiang et al. 2007). The Thornthwaite-Mather model (TM model) considers that runoff and/or percolation are the residual part of the superficial soil layer water balance: $S M S=P-E r-\Delta S$. This residual component is commonly called the soil moisture surplus (SMS), as it occurs when the maximum soil moisture capacity $\left(S_{\max }\right)$ is exceeded. In this balance, $P$ is the precipitation, $E r$ is the real evapotranspiration and $\Delta S$ is the change in storage. Soil water storage will increase or decrease, depending on the accumulated potential water losses (APLW). During dry periods, when potential evapotranspiration (PET) exceeds precipitation, APLW at month $t$ is given by equation (3). Storage must then be updated (equation (5)).

$$
\begin{aligned}
& A P L W_{t}=A P L W_{t-1}+\left(\sum P E T-\sum P\right) \\
& S_{t}=S_{\text {max }} \times \exp \left(A P L W / S_{\text {max }}\right)
\end{aligned}
$$


PET was calculated by the Thornthwaite method. During months when $P>P E T$, storage is updated $\left(S_{t}=S_{t-1}+P-P E T\right)$, limiting $S_{t}=S_{\max }$. Hence, the APLW is calculated:

$$
A P L W_{t}=S_{\max } \times \ln \left(S_{t} / S_{\max }\right)
$$

In both cases, when $S_{t}$ is obtained, the storage variation is calculated by $\Delta S=S_{t}-S_{t-1}$. Real evapotranspiration occurs as a function of water availability in the soil so equals $P E T$ when $\triangle S \geq$ 0 . If the soil moisture is lower $(\Delta S<0), E_{r}=P-|\Delta S|$. Then the deficit $\left(D E F=E T P-E_{r}\right)$ and water excess (soil moisture surplus) are calculated. If $\Delta S<0, \mathrm{SMS}=0$. When the soil moisture $S_{t}$ is equal to $\operatorname{Smax}, S M S=P-P E T-\triangle S$.

The percentages of $S M S$ that form percolation and runoff depend on the soil characteristics and its use (Jiang et al. 2007). Sridhar and Hubbard (2010) used a 50\% value for runoff in a very permeable sandy soil. Collick et al. (2009) also assumed that both percolation (Perc) and runoff (Roff) are derived from $S M S$, calibrating a parameter based on the baseflow recession curve to define the proportions of SMS that compose Perc and Roff.

\section{RESULTS}

The simulated precipitation was averaged by month through the 10 years and is given in Fig. 1 as a monthly mean value, plus or minus the standard deviation (light grey). Direct comparison of the model's simulations and experimental data would be inconclusive given that GCMs are free running and initialized with synthetic initial conditions (Jiang et al. 2013), so we used the mean values. The monthly mean observed precipitation fits well inside the median range of the models, indicating that the simulated and bias corrected values can represent precipitation in the study area on a monthly basis. The potential evapotranspiration values for the two crops, calculated from the measured and simulated temperature, are also shown in Fig. 1. For sugarcane and pasture the model calculated values are close those calculated from the experiment. As the temperature values were also close (data not shown) and are the main input in the Thornthwaite equation for evapotranspiration, it was expected that PET from the observed data and simulated data would be in good agreement.

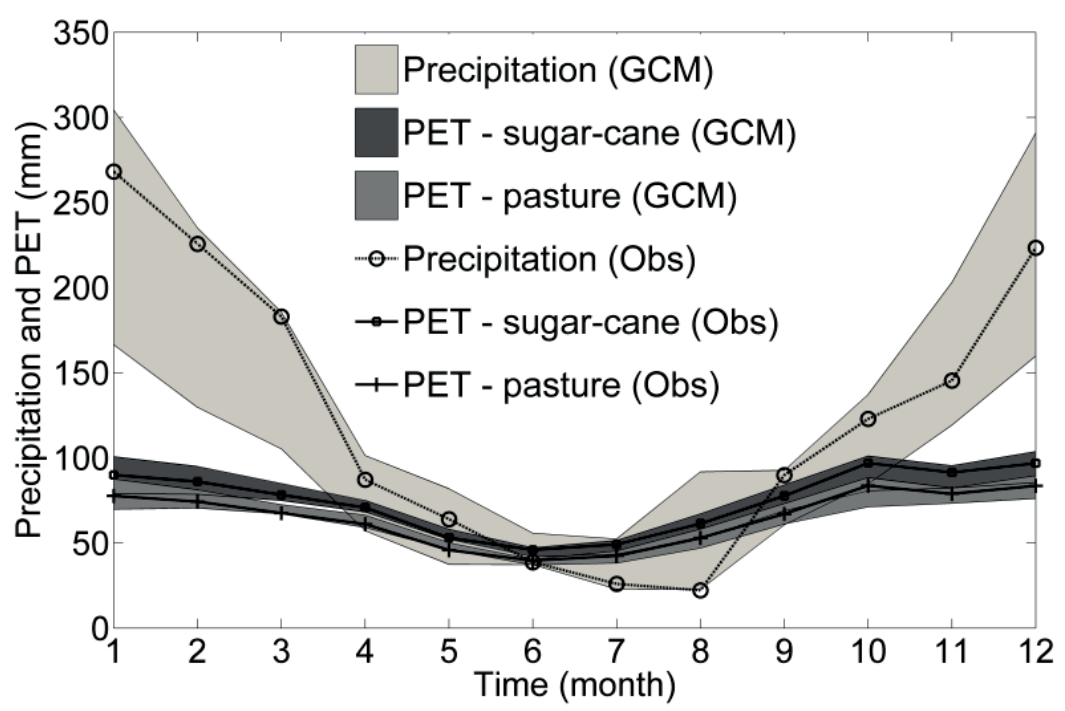

Fig. 1 Monthly averaged precipitation and PET variation range for years 1990-1999.

From the obtained data the annual soil moisture surplus $(A S M S)$ was calculated for all models (Fig. 2). Small circles stand for mean values; the upper and lower edges (upper and lower quartiles) of the boxplots are the values between which $50 \%$ of the values are found. Outliers are plotted as individual crosses. The average $A S M S$ value varies from around 300 to $500 \mathrm{~mm}$ for sugar cane and from around 600 to $900 \mathrm{~mm}$ for pasture. The average monthly values from all 10 


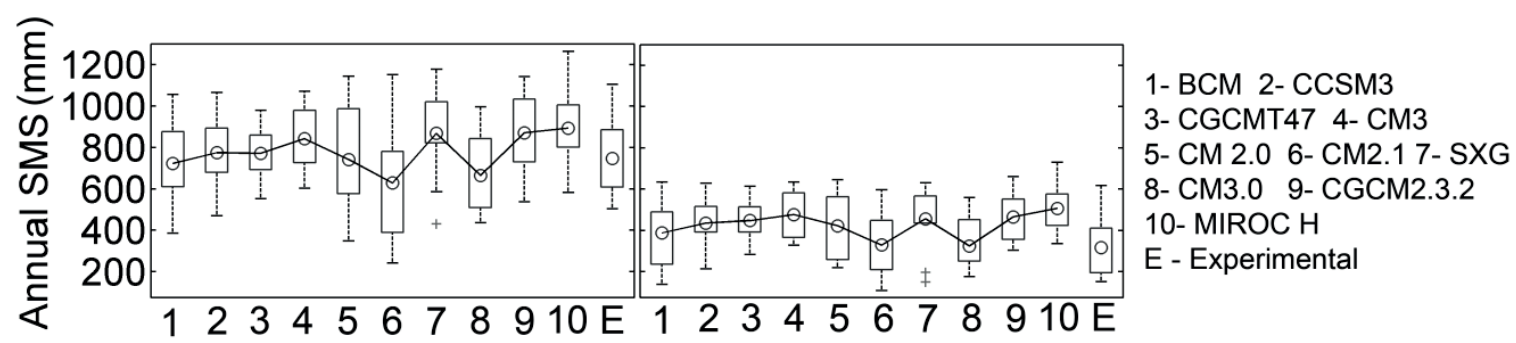

Fig. 2 Annual SMS for pasture (left) and sugar-cane (right). GCMs ASMS mean (circles) are connected by the line. Outliers are shown as small crosses.

GCMs over the entire period show a good correlation $\left(\mathrm{R}^{2}=0.94\right)$ with the surplus calculated from observed data. Considering that this value encompasses both runoff and percolation and that our study area has similar characteristics (highly permeable sandy soils) to that discussed by Sridhar and Hubbard (2010), we estimate that the total amount of moisture that can reach the water table is up to $50 \%$ of $A S M S$, or 150 to $250 \mathrm{~mm}$ (for sugar cane) and 300 to $450 \mathrm{~mm}$ (for pasture).

Figures 3 and 4 show the variability of the monthly SMS obtained from each GCM scenarios (GCM SMS). The SMS calculated from observed data (EXP SMS) for each month is also shown. The dry season (May-September) shows less variation than the wet season (October-April), with almost no SMS during the dry season. The outliers are a result of this small variation, as values just a bit higher than the average are plotted as outliers. For sugar cane planting, when comparing SMS from observed data, the GCM's SMS show a smaller variation range and lower maximum values in January and February (CM2.0 and CM2.1), although a few models do present behaviour similar to the observed data (BCM and INM CM3.0). BCM and CM3.0 include a soil reservoir but no groundwater component, while CM2.0 and CM2.1, for instance appear not to include surface water or groundwater at all (Meehl et al. 2007). The presence of outliers also indicates that models are overestimating the SMS during the dry season, which is not supported by the observed data, including much more SMS on November and December than EXP SMS. The influence of the crop type can be seen when comparing with pasture for dry season.

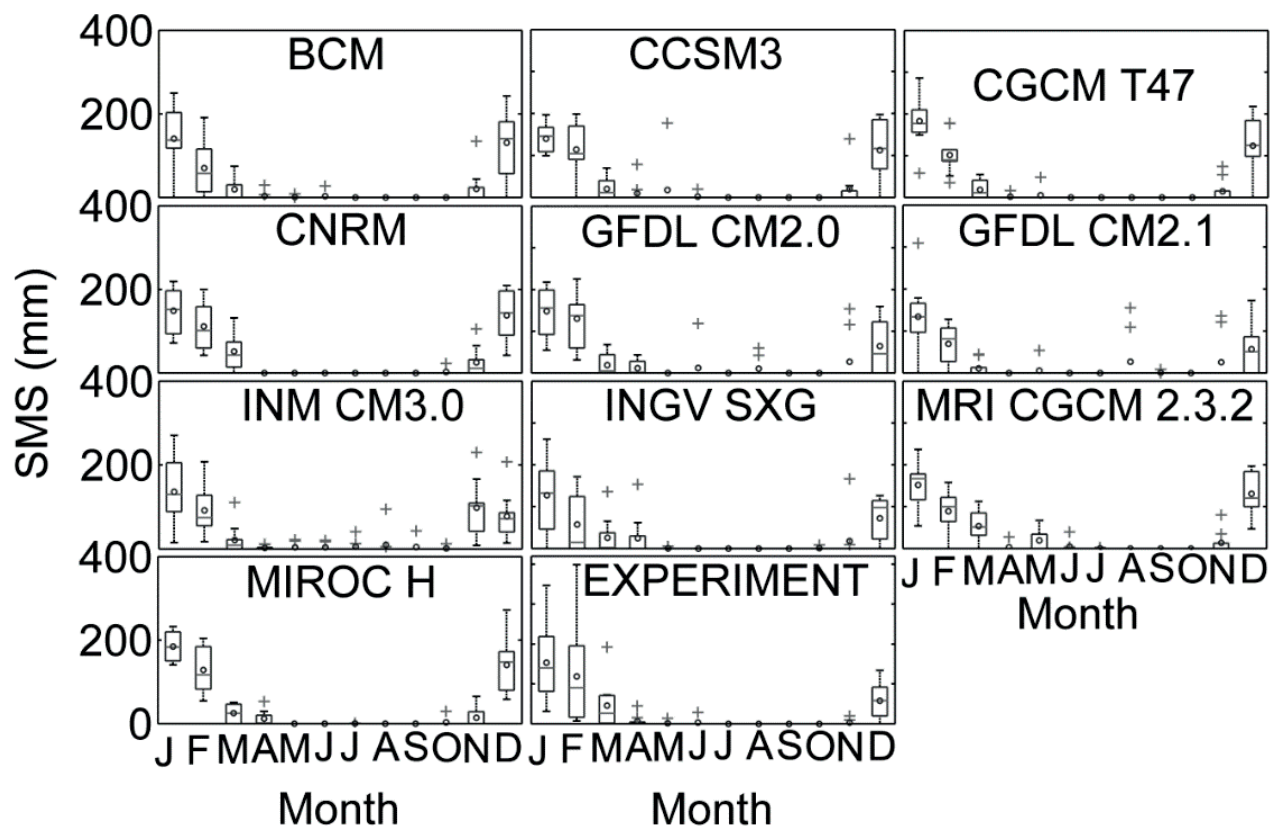

Fig. 3 Experimental and GCMs' monthly SMS for sugar cane planting. 


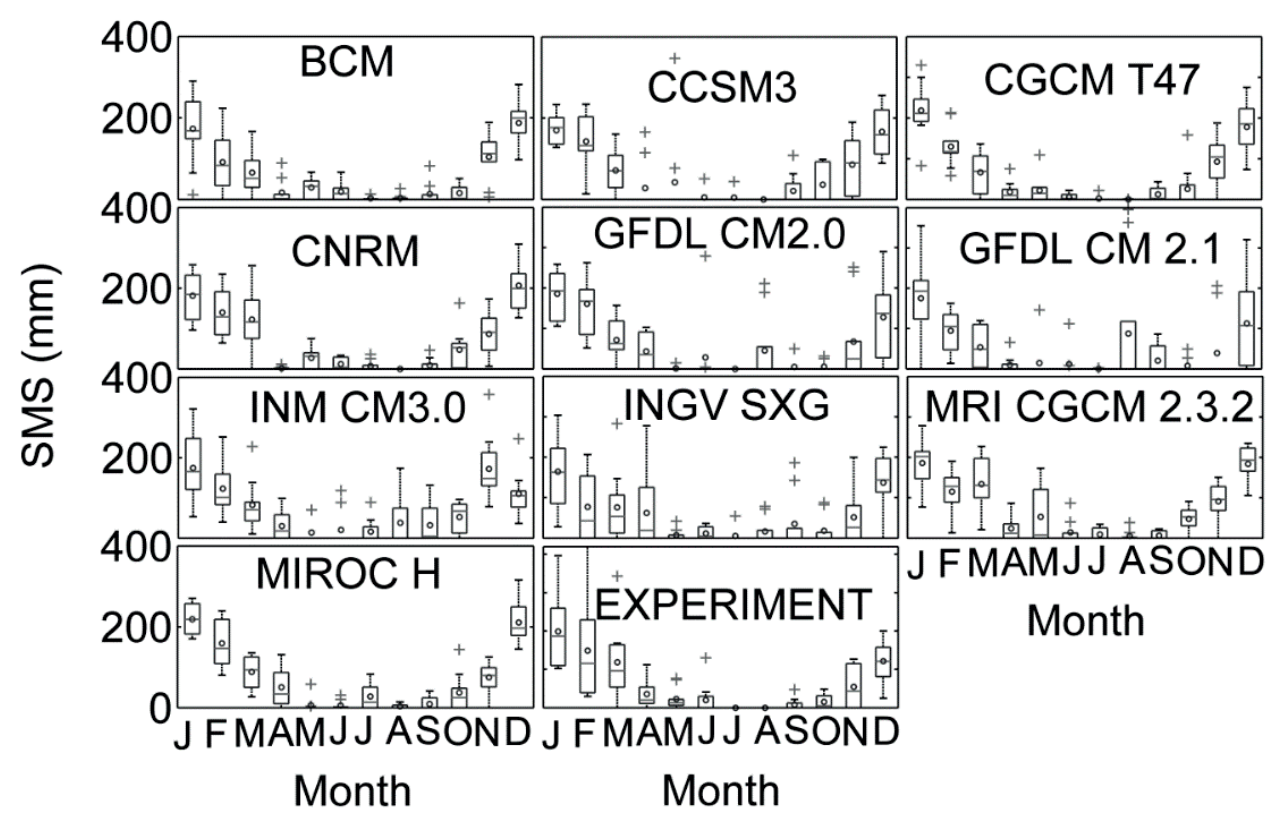

Fig. 4 Experimental and GCMs' monthly SMS for pasture.

For the pasture area, there is a much more significant SMS between May and September for both EXP SMS and GCM SMS. Some models continue to underestimate the maximum values and overestimate SMS during the dry season (CNRM CM3, INGV SXG, INM CM3.0, MIROC H), but to a lesser degree when compared to sugar cane. The increased number of outliers is due to localized extreme monthly rainfall values occurring in the dry season.

Although none of the models represent the EXP SMS well, there is a better agreement for the SMS pasture than the sugar cane during the dry season. This may be caused by the different crops and the way that the models represent surface vegetation cover. Sugar cane can more easily extract water from storage (due to its deeper root zone) than pasture and this process may be outside the soil moisture simulation envelope of most GCMs. For São Paulo state, for example, this assumption could lead to suboptimal representation of the surface vegetation cover as sugar cane occupies around $22 \%$ of the state area (Rudorff et al. 2010). Another possibility is that the land use considered by GCMs for calculating PET is more similar to pasture (such as grass) than sugar cane, leaving more water available to percolate or runoff.

A direct comparison of the water budgets calculated with observed data for the entire period, not just 2012, although more interesting, was not possible due to the lack of observed data. With the available observed data for the 2012 period, the water budget comparison presented a correlation of $\mathrm{R}^{2}>0.6$. In the sugar cane planting, the model water budget underestimated the $S M S$ during the dry season, presented a good correlation (0.91) during the wet season of the first year but underestimated by about $50 \%$ in the second year.

\section{CONCLUSIONS}

We presented a comparison of water budgets calculated from an ensemble of $10 \mathrm{GCM}$ scenarios and from data observed at an experimental site in São Paulo State. The monthly mean precipitation, temperature and evapotranspiration from the GCM scenarios lie inside the variability observed at the site. However, water budget results showed relevant differences, mainly for sugar cane plantation during the dry season.

A direct comparison of water budgets calculated with observed data and from GCMs was done with the data available for 2012. The results present differences that need to be better explored with more collected data.

In general, the GCMs' monthly soil moisture surplus overestimates the SMS calculated from observed data during the dry season and underestimate during the wet season. The annual SMS for 
sugar cane plantation showed a similar mean and variability as the SMS calculated with observed data. For pasture, experimental annual SMS presents a smaller mean and higher variability than most of the GCMs.

This indicates that, as the GCMs do not include groundwater in the modelling process, one of the other components of the water budget is offset to accommodate the difference. Given the importance of groundwater for global processes (such as SLR and other interactions of groundwater and surface water) this discrepancy must be better understood and evaluated. We understand that the difficulties involved in obtaining experimental data for these enhancements can be a big hurdle to be overcome, but the relevance of groundwater systems cannot be overlooked. A more integrated description of groundwater and surface water with atmospheric processes could lead to more precise global models and future forecasts.

Acknowledgements This work was supported by FAPESP grant 2011/19693-0 and CNPQ. The authors also acknowledge the valuable support provided by Cristian Youlton in accessing the data.

\section{REFERENCES}

Barthel, R., et al. (2012) Integrated modeling of global change impacts on agriculture and groundwater resource. Water Resources Management 26, 1929-1951.

Clark, R., Lawrence, A., and Foster, S. (1996) Groundwater: A threatened resource (United Nations Environment Programme Environment Library No. 15, Nairobi, Kenya.

Collick, A. S., et al. (2009) A simple semi-distributed water balance model for Ethiopian highlands. Hydrological Processes 23(26), 3718-3727.

IPCC (2007) Climate Change 2007 - The Physical Science Basis. Contribution of Working Groups I to the Fourth Assessment Report of the Intergovernmental Panel on Climate Change (ed. by S. Solomon et al.). Cambridge University Press, $996 \mathrm{p}$.

Jackson, C. R., Meister, R. and Prudhomme, C. (2011) Modelling the effects of climate change and its uncertainty on UK Chalk groundwater resources from an ensemble of global climate model projections. J. Hydrol. 399, 12-28.

Jiang, T., et al. (2007) Comparison of hydrological impacts of climate change simulated by six hydrological models in the Dongjiang Basin, South China. J. Hydrol. 336(3-4), 316-333.

Jiang, P., et al. (2013) How well do the GCMs/RCMs capture the multi-scale temporal variability of precipitation in the Southwestern United States? J. Hydrol, 479, 75-85.

Konikow, L. F. (2011) Contribution of global groundwater depletion to sea level rise. Geophys. Res. Lett. 38 , L17401.

Kløve, B., et al. (2013) Climate change impacts on groundwater and dependent ecosystems. J. Hydrol. (in press).

Meehl, G. A. et al. (2007) THE WCRP CMIP3 Multimodel Dataset: A new era in climate change research. Bull. Amer. Meteor. Soc. $88,1383-1394$.

Rudorff, B.F.T., et al. (2010). Studies on the rapid expansion of sugarcane for ethanol production in São Paulo State (Brazil) Using Landsat Data. Remote Sens. 2(4), 1057-1076.

Steenhuis, T. S. and Vandermolen, W. H. (1986). The Thornthwaite-Mather procedure as a simple engineering method to predict recharge. J. Hydrol, 84(3-4), 221-229.

Sridhar, V. and Hubbard, K. G. (2010). Estimation of the water balance using observed soil water in the Nebraska Sandhills. J. Hydrol. Engng 15(1), 70-78.

Youlton, C. and Wendland, E. (2012) Avaliação experimental do impacto da substituição de pastagem por cana de açúcar na produção de sedimentos. X Encontro Nacional de Engenhari de Sedimentos, Foz do Iguaçú, Paraná, December 2012. 